\section{ASCITES AND TUMOURS OF THE OVARY.*}

By E. EMRYS-ROBERTS, M.B., CH.B. VICT., M.D. LIVERP., SUB-CURATOR OF THE PATHOLOGICAL MUSEUM (GMA FOOLOGICAI SECTION), UAIVERSITY OF LIVERPOOL.

Amoxg the ancients ${ }^{* 1}$ ascites was a well-recognised pathological condition, treated precisely as at the present day, with results that owed their failure not to any error in procedure but to the want of the knowledge of the prevention of infection.

The term hydroperitoneum was introduced by Matthews Duncan ${ }^{23}$ for those cases where fluid is present but " no disease discovered, beyond the condition of the peritoneum, to which the collection of fluid can be referred, as for example hydrothorax and hydrocephalus." At the present day the necessarily artificial and arbitrary distinction between ascites and hydroperitoneum has been laid aside and the latter term has generally fallen into disuse.

The physiological characters of the peritoneum are those of a serous nembrane partaking in a very considerable fluid interchange; disturbance of the normal equilibrium leads to the production of ascites. ${ }^{42}$ "The cells of the endothelial wall," says Halliburton, ${ }^{30}$ "are alive and are capable of a selective action, which may mask or counteract or assist purely physical processes."

The ascites associated with hepatic cirrhosis is considered by certain writers 125850 to be an instance of an increase in transudation, combined with diminished absorptive powers, the result of a more or less mechanical obstruction to the venous return in the portal system. Stengel, ${ }^{5 \pm}$ however, states that " chronic peritonitis plays a part in the etiology of many cases of ascites ordinarily regarded as the result of obstruction of the circulation alone, as in cases of cirrhosis of the liver." Hawkins, ${ }^{31}$ although affirming that in cirrhosis of the liver the ascites is in 80 per cent. of the cases a direct result of portal obstruction, still retains an open mind with regard to the remaining 20 per cent. when he observes that "the relation between hepatitis, perihepatitis, and hepatic cirrhosis in the causation of ascites is not yet fully understood." In a recent article Kitchen and Thomson ${ }^{36}$ lay further stress on the toxic factor in the etiology of this disease, while it is stated in Jacobson and Rowlands's "Operations of Surgery" 35 that "it is more than probable that any good which may follow the operations which have been designed for establishing vascular anastomosis is really due more to the drainage carried out at the same time, and to the interference with the secretory function of the hepatic and splenic peritoneum.'

For the most satisfactory account of the pathology of ascites resulting from nephritis we are indebted to von Noorden ${ }^{60}$ who, in a masterly survey of the situation, declares that primarily "disturbances in water balance in nephritis are purely mechanical in origin-i.e., a direct relationship exists between the intake of water and the capacity for its excretion." At the same time he realises that " the presence of certain poisons in the blood favours the development of anasarca, making the walls of the capillaries more pervious, stimulating them to an 'active secretion." He agrees with Widal that a further etiological factor is the imperviousness of the kidney to chloride and its retention in the fluids of the body, but holds that hydræmia cannot be considered a factor, since "severe hydræmia never appears before the œedema, and hydræmia may be present without. œdema."

Thus modern thought assigns in nephritis, as in cirrhosis of the liver, an active as well as a passive rôle to the cells of the peritoneum; more work yet remains to be done in the elucidation of the toxic agents by which the peritoneal cells are stirred into activity.

The ascites arising from disease of the heart or lungs requires no elaborate explanation. Von Noorden ${ }^{60}$ voices the opinion of all authorities in his statement that "the excretion of water is insufficient, and hence it accumulates in the blood and tissues, together with other urinary substances, thus causing hydræmia and dropsy of the skin and serous cavities."

Ascites coincident with peritonitis, resulting from toxic

* A paper read at a meeting of the Liverpool Medical Institution on Feb. 6th, 1908, and illustrated by lantern slides. (The superior figures refer to the bibliography at the end of the article.) processes attending an infection of the peritoneum with micro-organisms, is in the form of an inflammatory exudation.

Hale White ${ }^{20}$ states that " ascites as a symptom of cancer of the liver may be absent even when there is pressure on the portal vein, corroborating the experiment of the ligaturing: of this vein in the dog. In many cases there is also chronic peritonitis due to malignant nodules in the peritoneum." A malignant peritoneal growth may possess an irritative or toxic property, as demonstrated under the microscope by round-celled infiltration at the growing margin, and the accompanying ascites may be as truly called a peritonitic exudation as in the case of infective peritonitis.

A French author ${ }^{58}$ describes a "thick viscid fluid, more or less resembling gelatine, sticky and adherent to the peritoneum and pelvic organs" as being associated with abdominal colloid cancer. It is not reasonable to suppose that the presence of a colloid growth could excite the peritoneum to the exudation of a colloid material ; more probable is the supposition that the growth itself is directly responsible for the colloid material, and if in the type of colloid cancer this is held to be a feasible explanation it is possible that the ascitic fluid of the usual type may in some cases be in its turn the product of the cancerous growth.

In ascites accompanying papilloma of the Fallopian tube ${ }^{2 t}$ it has yet to be proved that the secretion of a non-malignant growth in this situation possesses an irritative action upon the peritoneum.

A form of ascites occurring in young girls has been described by Quincke. ${ }^{29}$ This he states to be a "nervous form of hypersecretion." The literature seems to be confined to continental writers. ${ }^{6}{ }^{7}$ Stilling ${ }^{2}$ has described a neuropathic form of ascites. Klebs ${ }^{37}$ brings forward a class of ascites caused by fatty degeneration of the peritoneal epithelium. Ascites chylosus, ascites adiposus, hæmorrhagic ascites, hæmoperitoneum, choleperitoneum, ascites due to exposure, anæmia, and debility are fully described in the majority of the text-books.

In dealing with tumours of the ovary we are dealing with types of new growth of widely divergent pathology; the inferences drawn from the study of one type by no means necessarily apply to the other types. Ascites has been noted as a frequent accompaniment of fibroma of the ovary. Briggs ${ }^{10}$ describes it as being present in 40 per cent. of his cases. Doran ${ }^{22}$ states that it is of frequent occurrence. It is difficult to account satisfactorily for the presence of fluid in the abdomen in these cases. We find, in a discussion at a meeting of the British Gynæcological Society, that Macnaughton-Jones ${ }^{39}$ says that in the case he had brought forward the ascites was due, not to the presence of the tumour, but to alcoholic cirrhosis of the liver.

But while concurrent disease may account for a proportion of the cases it cannot be held to account for all. Donald 19 recently considered the presence in the abdomen of a tumour of low vitality sufficient to set up a chronic peritonitis, and that this was the pathological cause of the ascites. A fibroma may be a tumour of low vitality, in that the demands of its metabolism are not great, but it does not appear to be clear whyits presence should give rise to a peritonitis. At the same time we realise that fibromata of the ovary are prone to undergo necrosis on the one hand, and to suffer from torsion of the pedicle on the other. The latter condition would lead to renous and lymphatic congestion of the tumour and exudation of serum into the abdominal cavity, and, provided the torsion were not too severe, necrosis resulting would tend to further the increase in exudation, together with the establishment of a chronic peritonitis.

Necrosis-or necrobiosis-would appear to be a process, apart from accident, intimately associated with the lifehistory of the tumour; that it is not dependent upon restricted blood-supply is evidenced by the increased number and large size of the blood-vessels found when this process is established. It is, perhaps, more consistent with one's knowledge to say that if a benign tumour is of sufficiently slow growth its host may die before it has reached the stage of decar, while if the tumour reaches its allotted span of life whilst its host is still vigorous, then the pathological changes associated with degeneration are demonstrated. Necrosis, inviting infection by organisms either by means of the blood or more directly from the intestinal tract, would lead to a peritonitic exudation, which may account for a certain percentage of the cases. The histological characters of fibroma of the ovary negative any supposition that the tumour itself 
is capable of the production of ascites ; examination of the capsules of attenuated ovarian tissue covering certain of these tumours did not in one instance show any germinal epithelium, the only structure to which might have been assigned the property of fluid secretion. ${ }^{25}$

Compared with fibromyoma of the uterus, ascites accompanying ovarian fibroma is of frequent occurrence ; ${ }^{22}$ it is remarkable, indeed, how seldom ascites is found in this common uterine disease. A point of special interest and one worth investigating, considering their marked macroscopical and microscopical similarity, is whether ascites is present or absent as a rule in cases of large pedunculated subserous fibroids of the uterus, compared with pedunculated fibromata of the ovary. During the discussion following the reading of this paper Grimsdale described a case of ascites definitely dependent upon the mechanical irritation of the peritoneum by a calcified fibroma of the ovary, since the ascites regularly disappeared following complete rest and reappeared upon exertion. The pathology of the ascites associated with fibroma of the ovary would thus appear to be dependent upon necrosis of the tumour or torsion of its pedicle, upon mechanical irritation of the peritoneum by a hard tumour, upon concurrent disease, and lastly upon some cause hitherto undiscovered.

Ascites associated with multilocular adenomata or pseudomucinous cysts of the ovary is peculiarly interesting from the historical standpoint. Bristowe, ${ }^{13}$ for example, records a post-mortem examination where he found "a multilocular adenoma and fluid in the abdomen with marked peritonitis," but the appended history of the case would point to the peritonitis being probably the result of infection from a previous paracentesis. Indeed, in 1861 von Scanzoni ${ }^{61} \mathrm{de}-$ scribes paracentesis as one of the recognised methods of treatment for cysts of this description; in those days oöphorectomy was attended with such disastrous results that operators felt justified in resorting to the simpler expedient of emptying the tumour from time to time. Many tumours are wont to rupture spontaneously into the abdomen, often producing no symptoms at all of an adverse character. ${ }^{3126}{ }^{33}$ Penrose ${ }^{45}$ describes an interesting case of this description where "a large abdominal swelling underwent a rapid diminution, attended by sudden pain, followed in half an hour by the passing of a large amount of urine, with marked diuresis for four or five days. The tumour reappeared in one month's time, but during four days before admission was observed to slowly diminish, and to eventually disappear in three days' time; during the seven days abnormal quantities of urine were passed ; laparotomy revealed an ovarian cyst with straw-coloured gelatinous fluid in the abdomen." Cases have been recorded of traumatic as well as spontaneous rupture of these cysts. Storer asserts that peritonitis is less liable to supervene following upon traumatic rupture as compared with spontaneous rupture. An explanation for this statement may be made on the grounds that the latter contingency may result from necrotic softening of the cyst wall, ${ }^{61}$ thus favouring the incursion of organisms, or from a malignant condition of the cyst with results resembling those described under ascites associated with malignant disease of the peritoneum. The irritative action of the contents of this class of ovarian cyst inducing a state of chronic peritonitis has been suggested by Bristowe ${ }^{11}$ and recently by Pozzi, ${ }^{4 \times}$ but after excluding infection from paracentesis, necrosis, and malignancy, there would appear to be no grounds for the suggestion. The attitude of the modern surgeon to the cystic contents is one of indifference, and this attitude, based upon clinical experience, supports the view that under normal conditions the fluid contained in pseudomucinous cysts is innocuous and non-irritative. Ascites, generally in scanty proportions, occasionally accompanies unruptured cysts and cysts that show old cicatrices; in some instances its presence may be induced by a necrotic state of the cyst wall or torsion of the pedicle; at least it cannot be said to be a transudate of the fluid from within the cyst, seeing that these cysts may reach very large sizes with little or no accompanying ascites. Ascites, then, with pseudo-mucinous cysts may accompany necrosis of the cyst wall and torsion of the pedicle, or may result from rupture, spontaneous or traumatic, of the cyst itself.

Lastly, we come to the type of ovarian tumours distinguished by papillomatous growth. This may be divided into three classes: (1) those in which the papillomatous projections are purely intracystic, (2) those in which the projections are both intracystic and extracystic, and tumours characterised by superficial papillæ only. The first class, with which may be associated the serous cysts of the ovary, are not known, apart from rupture, to produce ascites, and there is no suggestion in the literature that their limpid contents, when poured out into the peritoneum, following rupture of the cyst wall, possess any irritative action. Barnes ${ }^{2}$ has stated that "when a tumour bursts with escape of its contents into the peritoneum the fluid if limpid may be taken up into the circulation and discharged rapidly by the excretory organs." For the purpose of this paper Class 3 , the primary superficial papilloma, may 'be discussed along with Class 2, where intracystic and extracystic papillomata coexist; this latter class accounts, according to Pozzi, ${ }^{48}$ for the great majority of the cases of ascites associated with ovarian tumours. Doran ${ }^{22}$ states that in this class ascites is rarely, if ever, absent, and an exhaustive survey of the literature confirms this opinion. Bouilly ${ }^{8}$ goes even further and affirms that "ascites is an invariable symptom of superficial papilloma of the ovary." The only explanation one has been able to discover regarding the pathology of this condition is that offered by a French writer, Menetrier, ${ }^{10}$ who considers the ascites to be "fluid exuded from the peritoneum under the irritative influence of the tumour." All the other authorities draw attention to the coexistence of ascites with this class of ovarian tumour, but do not appear to have assigned its presence to any pathological factor. It has fallen to my lot elsewhere ${ }^{25}$ to record an explanation for this condition based upon the histological examination of a primary superficial papilloma of the ovary. Briefly stated, the epithelium covering the new growth of the ovary, agreeing in all respects with the epithelium covering intracystic papillomata and partaking of the physiological characters of this epithelium, determines the cause of the ascites to be the secretory activity of the cells covering the superficial papilloma of the ovary.

Whitridge Williams ${ }^{63}$ states that " the watery consistency of papillomatous cysts is probably due to the fact that there are but few mucigenous cells in the epithelial lining and also because a considerable portion of the fluid is a transudation from the vessels in the papillary projections." One's knowledge of this class of tumours corroborates the first portion of this statement but it is difficult to understand how he arrives at the conclusion that a considerable portion of the fluid is a transudate from the capillary vessels in the papillary projections. In an examination of the fluids he gives the specific gravity as ranging between 1005 and 1040 . Wells, ${ }^{62}$ in an investigation into the contents of cysts almost identical with papillomata of the ovary, gives the following figures:--Papillary intraligamentary cysts, specific gravity 1032 to 1036 , solids 9 to 10 per cent.; serous cysts of the ovary, specific gravity 1005 to 1014, solids 1 to 4 per cent.; and parovarian cysts, specific gravity under 1010, solids 1 to 2 per cent., the ash often 80 per cent. Comparing these figures with those of blood plasma ${ }^{30}$ specific gravity 1026 to 1029 , solids 10 per cent., of which eight parts are proteid--we see that the fluids are not merely transudates from capillary vessels but result from a selective secretory action on the part of the lining epithelium, which agrees with Halliburton's ${ }^{30}$ definition of that structure in that "it consists essentially of a layer of secreting cells arranged around a central cavity, taking from the lymph which bathes them the necessary material and transforming it into the secretion which they pour at high pressure into the cavity." Histological evidence 25 proves that not only is the epithelium of an intracystic papilloma a secretory epithelium but so also is the epithelium covering the extracystic and superficial papilloma, and as there is no evidence that the secretion is of an irritating character, the presence of free fluid in the abdomen associated with intracystic papillomata with extracystic growth and with superficial papillomata of the ovary is to be regarded as the result of an active secretion on the part of the epithelium covering the growths. Fluid absorption, as we have seen, plays an important part in the physiology of the peritoneum; that the fluid secreted by the growth is incapable of absorption is improbable when one considers the limpid character of the secretion of cystic papillomata; more probable is the explanation that the rate of fluid secretion by the growth is in excess of the rate of absorption by the peritoneum.

Ascites, then, we have seen to be in essence an interference with the absorptive powers of the peritoneum; either the absorption is diminished or else the fluid production is 
in excess of the absorption; and we have also seen that all forms of ascites are not dependent upon increased transudation from the peritoneum. In addition it has been shown that the tendency of modern investigation is to assign to the cells of the peritoneum a more active rôle in the production of ascites, while at the same time instances have been brought forward of ascitic production not dependent upon the peritoneal cells but resulting from the activity of certain epithelial cells developed in tumours both of the ovaries and of the Fallopian tubes.

Lastly, we realise that the ascites accompanying tumours of the ovary may result from certain necrotic changes undergone by the tumours, from torsion of their pedicles, or from mechanical irritation of the peritoneum by tumours of extreme hardness. At other times the fluid in the abdomen may be accounted for by concurrent disease, or may require an explanation which is so far not forthcoming, while in certain tumours the ascites is actually the product of the epithelium of these new growths, as, for example, superficial papillomata and cystomata with ruptured walls.

Bibliography. $\rightarrow$ Allbutt, Playfair, and Eden : System of Gynacology,
1906, 1906, p. 428. 2 Barnes : Diseases of Women, second edition, 1868, p. 392.' Ovar. und seine Beziehungen zu Keimepithelcysten, Zirich, 1903 Travail de l'Inst. Anat.-Path. de la Fac. de Zürich Gyn. Hebet., 1903, p. 96. 4 Bidwell: Some Cases of Ascites Treated by Abdominal Sutton, Trans. Clin. Soc. Lond., vol. Xxxiv., p. 171. s Blandp. 777. 6 Bouilly: De l'Ascite des Jeunes Filles, Rev, prat. de Par., 1897, 221-225. \& Bouilly: Le Prognostic des Kystes Végétants de lovaire, Congrès Français de Chirurg., Octobre. 1897; Abs. in Path. of the Renal Functions, Allbut's System of Medicine, 1899, Path. of the Renal Functions, Allbutt's System of Medicine, 1899,
p. 322. 10 Briggs: The Path. of Solid Ovarian Tumours, Trans. N. of p. 322. 10 Briggs: The Path. of Solid Ovarian Tumours, Trans. N. of Ascites treated Successfully with Tonics, Trans. Clin. Soc. Lond. vol. ii., p. 142. 12 Bristowe, J. S. : Ovarian Tumour; Discharge of Cantents into Abdom. Cav.; Condition of Perit. resembling Colloid Cancer, Trans. Path. Soc., vol. xii., p. 150.13 Bristowe, J. S. p. 226. 14 Chavannaz: Papill. Myxo-Epithelioma of Ovary with Gelat. Ascites, La Gynec., June, 1905; Abs. in Brit. Gyn. Journ., und Veränderten Theirischen Peritoneums, Wien. Klin. Wochenschr., 1902, No. 45. 16 Coupland : Dissem. Nodular Growths in the Liver, \&c., Trans. Path. Soc., vol. xxv., p. 142. 17 Croft : Pap. Cyst of Ovary with Ascites, Trans. N. of E., Obst. and Grn. Soc. Oct. 17th, 1902. 18 Dickinson: W. H. : Case of Colloid Cancer, Trans. Path. Soc. p. 87. ' 29 Doran : Ovarian Tumours Simulating Inflamed Ovaries, Tube Assoc. with Ascites and Ple p. 453. 2i Doran: Papill. of the Fall. Tube Assoc. with Ascites and Pleuritic Effusion, Trans. Path. Soc., vol. xxxi., p. 174. 22 Doran: In Butlin's Operative Surgery of Malig. Dis. peritoneum, Med. Times and Gazette, 1899, vol. ii., p. 547. On Hydrogeritoneum, Med. Times and Gazette, 1899, vol. ii., p. 547. 24 Elder: 25 Emrys-Roberts: A Contribution to the Study of Superficial 25 Emrys-Roberts: A Contribution to the Study of Superficial Papilloma of the Ovary, Journ. of Obst. and Gyn., Feb., 1908. Virchow's Archiv, vol xliii, p. 14. 27 Haie White: Clin. Journ., A pri Virchow's Archiv, vol. xliii., p. 14. 27 Hale White: Clin. Journ., Apri 25th, 1898. 28 Hale White: Perihepatitis, Allbutt's Syst. of Med., 1899,
p. 120. 29 Hale White : Tumours of the Liver, ibid., p. 199. 30 Halliburton: Handbk. of Phys., sixth edition, 1904, pp. 471, 320 . 31 Hawkins: Cirrhosis of the Liver, Allbutt's Syst. of Med., 1899, p. 176. 32 Hewitt: Diseases of Women, 1863, p. 148. 33 Hoermann: False Ascites Assoc. with Ov. Tumours, Munchener m. Wochens., 1905, March 21st; Abs. in Brit. Gyn. Journ., 1905-06. 31 Holmes: Ovariotomy, Rupt. of the Cyst into the Perit. before Oper. without Sympts. Trans. Path. Soc, vol. xv., p. 161. 35 Jacobson and Rowlands: The Operations of Surgery, fifth edition, 1907, vol. ii., p. 542. 36 Kitchen and Thomson: Some Remarks on Ascites, Practitioner, Dec, 1907, p. 832 in Animal Metabolism, 1906, p. 143. 39 Macnaughton-Jones : Discussion on Fibroma of Ovary with Ascites, Brit. Gyn. Journ., vol. xxi., 1905-06, on Fibroma or Ovary with Ascites, Brit. Gyn. Journ., vol. xxi., 1905-06,
p. 4. 40 Menetrier: Les Tumeurs, Traité de Path. Géneral, tomeii., 1900,
p. 749. 4l Moullin, Mansell : The Treatment of Ascites by Fixation of the Omentum, \&c., Trans. Clin. Soc. Lond., vol. xxxv.. p. 14. 42 Nothnagel Omentum, \&e., Trans. Clin. Soc. Lond., vol. Xxxv..p. $14 .{ }^{2}$ Nothnagel : Fincyclopædia of Pract. Med., 1904, pp. 692-3-4-5-7. 43 Osler: Princip. and Pract. of Mer., sixth edition, 1905 , p. 590. 44 Paulus Agineta:

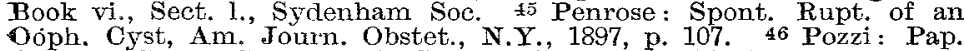
Ooph. Cyst, Am. Journ. Obstet., N.Y., 1897, p. 107. 46 Pozzi : Pap. Ovarian Cysts, Centralb. f. Gynäk., Leipzig, 1905, No. 9; Abs. in
Edin. Med. Journ., 1905, vol. xviii., p. 276 . I7 Pozzi : Pap. Cysts and Tums, of Ov., Rev. de Grnée. et de Chirurg. Abd., 1904, p. 407. 48 Pozzi Traité de Gynécol., 1907, tome 2nd, p. 955. ${ }^{49}$ Quincke: Ascites, D. A. f. Klin. Med., xvi., 1875. 50 Roberts : In Quain's Dict. of Med., 1902, p. 105. 51 Seligmann: Two Large Pap. Tums. of Ov., Soc. Obsts.,
Hamburg, June 9th, 1903; Ahs. in Rev. de Gynéc. et de Chirurg. Abd., 1904, p. 837. 52 Smrly: Ov. Pap., Roy. Acad. of Med. Ire., April, 1903 Abs. in Journ. of Obst. and Gyn., 1903. 53 Spencer Wells: Two OV Cysts Rupt. Spont., Trans. Path. Soe., vol. X., p. 196. 54 Stengel Text-book of Path., third edition, 1900 , p. 569. s5 storer: Traum. Rupt. of Ot. Cysts, Boston Med. and Surg, Journ., vol. it Thornton, Knowsley : Tums. of both Ors. with Pert. Infect, Trans. Path. Soc., vol. xxviii,, p. 189. 58 Traité de Médecine, tome iii., 1892, p. 189. 59 'Twentieth Century Practice of Medicine, vol. vii., 1897, p. 502-3-5-15. 61 Von Scanzoni : Diseases of Women, fourth Amer. edition (circ. 1861), pp. 431-9 and 456. 62 Wells: Chem. Path., pp. 424, The Johns Hopkins Hospital Reports, vol. iii., 1893, p. 5 . University of Liverpool.

\section{THE INDIVIDUAL PLASMA.}

\section{By Professor R. FICK,}

VORSTAND DES ANATOMTSGHEN INSTITUTS DER K.K. DEUTSCHEN UNIVERSITÄT, PRAG.

MANY writers have maintained, among them Nägeli and O. Hertwig, that the body cells of every organism must contain a special modification of the living substance or protoplasm peculiar to itself. This Nägeli called "Idioplasm." In this special form of protoplasm the characteristic properties of the particular organism must be contained-e.g. the protoplasm of the cat must be different from that of the dog or hare, and so forth, as is indicated by the chemical differences in the fat, bile acids, blood colouring matter of different animals, as well as by their different susceptibility to certain diseases.

In my opinion it is a logical necessity to go further and to assume that in the cells of each individual there must be a special form of protoplasm which I propose to call "individual plasma." This individual characteristic specific form of protoplasm must be already contained in the fertilised ovum cell of each organism. In it must be present all conditions necessary for the complete development of these cells into the individual organism which is ultimately to proceed from it. In other words, there must be present in this individual plasma the predisposing conditions (Anlagen) which determine the development of all the inherited characteristics which are to be subsequently observed in the particular individual in question. It follows then that every child of every pair of parents must have a different individual plasma and the individual plasma may therefore be defined as the specific protoplasm of the individual. The behaviour of different individuals towards infections, the occurrence of individual immunity towards many diseases, the specific smell-i.e., the specific exhalation-of every individual which can often be so clearly distinguished, as, for example by dogs, all speak in favour of these views. The adult organism naturally transmits its own individual plasma to the germ cells produced by it whether ovum or sperm.

The individual plasma is evidently, like all forms of protoplasm, to be regarded as a living organised substance formed of different albumin-like chemical groups. Weismann has stated that each heritable characteristic in a species or individual-e.g., the black spots in apple-mould, the special tufts on the wings of a butterfly, and so onmust correspond with a slight modification in the properties of the ovum or sperm. Weismann supposes that every such characteristic-e.g., every hair and every scale in such a spot-is represented in the germ-cell by a more or less isolated corporate particle which he calls a "determinant" (Darwin's "gemmules," de Vries's " pangenes"). I do not, however, believe that these separate determinants (Anlagen) require such isolated material particles, but perhaps only special atom-groups, or it may be only special arrangements of atoms or atom-groups, in the molecules of the individual plasma.

According to my view a change in the position of an atom or atom-group in the molecule of the individual plasma would be sufficient to bring about such a change in development that in the fully developed organism some special marke.g., a white bundle of hairs in any part of the scalp-would develop, which might afterwards be inherited. The individual determinants are then, in my view, intra-molecular in the individual plasma. According to my hypothesis there must be as many different kinds of protoplasm as there are individuals upon the earth. This might seem impossible. As a matter of fact, Herbert Spencer believed that the ultimate life-units could not be composed of separate molecules, because so many different molecules could not exist, but that they must be differently constituted molecules and consequently the life-units were specifically different.

Modern chemistry shows that a molecule of albumin contains 40 asymmetrical carbon atoms-i.e., carbon atoms with which four different atoms or atom groups are combined. If this be the case then within that molecule about a billion different arrangements in space, so-called stereoisomers, are possible. To these must be added almost as many arrangements for the nitrogen atoms and unsaturated groups. Yet with all these intra-molecular changes the percentage composition-i.e., the empirical molecular formula-would remain the same. It is therefore no chemical impossibility, but on the contrary theoretically 